\title{
EDITORIAL: THE YEAR OF THE LUNG 2010: the Year of the Lung
}

\author{
N.M. Siafakas*, M. Decramer ${ }^{\#}$ and K.F. Rabe
}

D ulmonologists and respiratory scientists believe that respiratory health and disease are neglected by the public, politicians and the health policy makers in the world [1]. We may be biased [2] but the numbers are strongly in support of this opening statement. One example is the funding for respiratory research which is inadequate. In the UK in 2002 respiratory research only claimed $2.8 \%$ of the Medical Research Council budget, while 13\% of mortality was due to respiratory disease [3]. Similar estimations have been made in other countries. The global prevalence of respiratory disease also supports this statement. In a recent estimate, the World Health Organization (WHO) considers respiratory diseases to be the second leading cause of death after cardiovascular diseases. In addition, mortality from cardiovascular diseases is decreasing in prevalence but mortality from lung diseases is on the rise [4]. For example, chronic obstructive pulmonary disease (COPD) will become the third cause of death in the world by the year 2020, from the sixth position on the mortality scale in 1990 [5]. Adding up the prevalence of all respiratory diseases (asthma, COPD, lung cancer, tuberculosis, pneumonias and sleep-disordered breathing among others) shows that almost a billion people worldwide are struggling to breathe and that almost 12 million will die each year as a result. Although lung diseases affect people in every country, the poor, the old, the young and the weak are the most affected [6].

Tobacco smoking, which remains legal, causes more than 5 million deaths each year and affects the health of millions of others due to passive smoking. Furthermore, tuberculosis is on the rise worldwide with more than a million new cases and 1.7 million deaths per year [7]. In addition, pneumonia kills more than 2 million children each year despite the fact that it is perfectly treatable. Most of the 250,000 deaths from asthma each year are attributed to the fact that proper treatment is not available in all countries. Finally, WHO estimates that half of the world's population lives in or very near areas with poor air quality $[8,9]$. Despite these terrifying global statistics, public demand and political commitment remain inadequate.

Thus, the Forum of the International Respiratory Societies (FIRS), composed by the ATS, ACCP, ALAT, APRS PATS, IUATLD and European Respiratory Society (ERS), had declared 2010 the Year of the Lung (YoL). The main objectives of this campaign are to: increase awareness for lung health and

*ERS Past President, University of Crete, Heraklion, Greece. ${ }^{*}$ ERS President, University of Leuven, Leuven, Belgium. "ERS President Elect, University of Kiel, Kiel and Clinic Grosshansdorf, Germany.

CORRESPONDENCE: N.M. Siafakas, University of Crete, Heraklion, 71110, Greece, siafak@ med.uoc.gr to advocate for policy actions to combat them; increase resources for basic and clinical research; convey the message that prevention of lung disease is highly cost-effective; and insist on clean indoor and outdoor air that is a fundamental right of all human beings [6]. The international Societies have signed the YoL declaration, raised their voices to fight respiratory disease and become the responsible society of actions in their continent. ERS have coordinated the YoL events in Europe.

The YoL in Europe was successfully launched in Marseille, France during the Congrès de Pneumologie de Langue Française (CPLF; January 2010). The entire campaign was based on the joint efforts of all the National Respiratory Societies of Europe (Forum of European Respiratory Societies). During 2010 a great number of events have taken place across Europe under the auspices of the YoL. For example, the Annual Congress of each of the National Respiratory Societies were $\mathrm{YoL}$ events and were used to the attention of the press, the public and the Government in each country.

Moreover, ERS has concentrated its efforts on Pan European legislating bodies, such as the European Parliament, the European Commission, the European Health Ministers and the European Government holding the EU Presidency, as well as global organisations such as WHO. ERS has organised several events in the European Parliament to promote clean air in Europe and in March 2010 launched the Air Quality and Health booklet [10] to discuss the priorities in respiratory research and convince the members of the European Parliament to increase the funding of lung research and include them in the Framework Programme 8 (April 13), to promote prevention of Asthma (May 4) or to enhance the fight against tobacco (May 31) or COPD (June 28). Furthermore, during the ERS Annual Congress in Barcelona (September 1822), the largest ever global meeting of pulmonologists, a number of YoL events were dedicated to increasing the awareness of respiratory diseases, including the Opening Ceremony.

In October 2010 two major events took place, World Spirometry Day (WSD; October 14) and the pre-ministerial conference in Brussels, Belgium (October 18-19).

WSD Day was a global event planned by the members of FIRS and YoL partners, and was coordinated by ERS. With the help of the European Lung Foundation (ELF), our patient organisation, ERS has promoted the usefulness of spirometry in early diagnosis of various respiratory diseases. The aim of this event was to perform as many free spirometry tests on the same day across the world in order to capture the interest of the press and the public. The results exceeded expectation with more 
than 72 countries participating across more than 700 sites. To date, more than 85,000 measurements have been recorded. From Australia to North and South America, Europe to Africa, pulmonologists, respiratory therapists, respiratory technicians and other related scientists showed that they could join forces to raise awareness on lung health issues through a global project.

On October 19, ERS organised the first ever high-level conference on chronic respiratory disease under the format of a pre-ministerial conference. This conference assembled more than 120 healthcare professionals, patients, pharmaceutical industry employees and health-policy makers. ERS also used this conference to launch its respiratory Roadmap initiative; a set of recommendations and action plans for health-policy makers to help them deal with the epidemic of chronic respiratory disease in the coming decades. This was followed by a ministerial conference on October 20, where the ERS President summarised the highlights of the pre-ministerial conference for the European ministers of health and the top European health-policy makers and made specific recommendations that will hopefully influence the decisions and resolutions to be drawn up by the European Council in December.

Globally, the YoL initiative was also active during World COPD Day (November 18), World Pneumonia Day (November 12) and other days devoted to specific lung disease, increasing the visibility of respiratory health. Finally, the YoL closing event in Europe took place in Portugal during the Annual Congress of the Portuguese Respiratory Society.

In conclusion, we consider the YoL campaign to raise awareness on lung health and call to arms for all pulmonologists across the world to be united against respiratory disease a huge successful. We have been surprised by the global positive response demonstrating the usefulness of the campaign which deserved the maximum attention. Now that awareness has been raised it is time to step forward with action plans and solutions and attempt to integrate them into the existing National, European and Global action plans.

\section{STATEMENT OF INTEREST}

Statements of interest for all authors of this manuscript can be found at www.erj.ersjournals.com/site/misc/statements.xhtml

\section{REFERENCES}

1 Siafakas NM, Vermeire P, Pride NB, et al. Optimal assessment and management of chronic obstructive pulmonary disease (COPD). The European Respiratory Task Force. Eur Respir J 1995; 8: 1398-1420.

2 Rabe KF, Decramer M, Siafakas NM. The Year of the Lung. Lancet 2010; 376: 753-754

3 Laurent GL. Getting grand applications funded: lessons from the past and advice for the future. Thorax 2004; 59: 1010-1011.

4 WHO Global Alliance against Chronic Respiratory Diseases. Stop the global epidemic of chronic disease. www.who.int/gard/en Date last accessed: August 31, 2010.

5 Pauwels RA, Rabe KF. Burden and clinical features of chronic obstructive pulmonary disease (COPD). Lancet 2004; 364: 613-620.

6 www.yearofthelung.org Date last accessed: August 31, 2010.

7 Centers for Disease Control and Prevention (CDC). State-specific smoking-attributable mortality and years of potential life lost United States, 2000-2004. MMWR Morb Mortal Wkly Rep 2009; 58: 29-33.

8 World Health Organization. Chronic respiratory diseases. www. who.int/respiratory/en Date last accessed: August 31, 2010.

9 Salvi SS, Barnes PJ. Chronic obstructive pulmonary disease in nonsmokers. Lancet 2009; 374: 733-743.

10 Künzli N, Perez L, Rapp R. Air Quality and Health. Sheffield, European Respiratory Society, 2010. 